\title{
Shooting ourselves in the foot: why mandatory reporting of gunshot wounds is a bad idea
}

\author{
Merril A. Pauls, Jocelyn Downie
}

ß See related articles pages 1256 and 1258

A recent position statement by the Ontario Medical Association's Section on Emergency Medicine called on the Ontario government to pass a law requiring physicians to report gunshot wounds to police. ${ }^{1}$ The Ontario government quickly passed a motion to "introduce legislation to require hospitals and physicians to report gunshot wounds and knife injuries to their local police service." ${ }^{2}$ The goals behind the position statement are laudable: "to assess and reduce immediate public risk and to collect data to inform future prevention strategies." 1 However, mandating that physicians report gunshot wounds is an ill-conceived response to the problem of gun-related violence. It will produce little benefit and cause significant harm.

Proponents of mandatory reporting of gunshot wounds argue that police must be contacted to investigate the incident, determine the risk to the public and intervene to prevent future violence. However, available statistics on violence involving guns call into question whether a police investigation is the most effective and efficient way to prevent further violence and protect the public. In 1997 in Canada, approximately $4 \%$ of Canadian firearm-related deaths were accidental, $78 \%$ were suicidal and $15 \%$ were homicidal. ${ }^{3}$ For firearm-related injuries requiring hospital admission between 1997 and 1998, 38\% were classified as accidental, $26 \%$ as self-inflicted and $26 \%$ as inflicted by others. ${ }^{4}$ Education and safety training would be a better strategy for preventing accidental firearm injuries and deaths than would police notification. Furthermore, patients who attempt suicide with a firearm require psychiatric care, not a police investigation. Victims of accidental and self-inflicted gunshot wounds (the majority of cases) pose little risk to the public at large. In cases where the gunshot wound has been inflicted by another person, the position statement refers to anecdotes from physicians concerned about "gangs invading EDs to 'finish the job" or innocent-looking gunshot wound victims who may be "dangerous criminals." In fact, most firearm homicides are impulsive acts involving people who know each other, ${ }^{5}$ not premeditated revenge killings by hardened criminals. The latter situation is very rare, and even if the concerns expressed are legitimate, the proposed legislation is far too sweeping.

A second argument presented in the position statement is that data on the number, nature, costs and circumstances of gunshot wounds would help policy-makers formulate strate- gies to prevent such injuries. The authors claim that mandatory reporting will provide such data. However, these data could be collected without disclosing the identity of patients with gunshot wounds. Research could be conducted, and beneficial results realized, without compelling physicians to breach confidentiality, particularly to the police.

The position statement also argues that society has accepted mandatory reporting laws in other areas, such as suspected child abuse, impaired driving and certain infectious diseases. There are significant differences between these situations and the case of gunshot wounds. Children are a vulnerable group and are usually unable to prevent ongoing abuse without the help of others. Impaired drivers represent a clear risk to others, and the removal of their licences should (at least in theory) decrease that risk. Similarly, a patient with a reportable infectious disease poses a direct risk to others, and intervention can mitigate or eliminate the risk. In the case of a gunshot wound, the person being reported may or may not pose a risk to the public. There is no clear intervention that can be undertaken to mitigate or eliminate this undefined, and probably undefinable, risk. Under these current mandatory reporting laws, patient information does not go to the police, but to other agencies (which have a duty of confidentiality) that investigate the actual risk posed and involve police only if they deem it necessary.

Emergency physicians become aware of many different criminal activities in the course of their duties. Following the logic that all serious crime should be reported to police, one could argue for the mandatory reporting of domestic violence, stabbings, assaults and illicit drug use, along with gunshot wounds. The position statement calls for the mandatory reporting of gunshot wounds, but the motion for legislation calls for mandatory reporting of gunshot wounds and knife injuries. This takes us some way down a slippery slope. Physicians already have a duty to relay a warning when they become aware of an imminent threat of serious bodily harm to an identifiable person or group. ${ }^{6}$ If a patient with a gunshot wound fits these criteria, in circumstances in which the threat is reasonably believed, a physician should report this to police.

The position statement hardly addresses one of the most disturbing aspects of a mandatory reporting law for gunshot wounds. Should physicians and hospitals be acting as an extension of the police in such an obvious and sweeping manner? Patients disclose information to their physicians 
that they rarely reveal to anyone - about their drug and alcohol use, their sexual practices, the violence they suffer and many other personal and private matters. They do so because they want to get well, and they trust that their physician is committed to this same goal. They share this information with the understanding that it will be used to help them, not to initiate a police investigation. If physicians are obliged to report gunshot wounds, the real danger is not that a few people may be deterred from seeking care, but that many others, who see that physicians have become an extension of the police force, will choose not to reveal their drug use, will refuse to say how they received an injury or will not disclose their sexual practices for fear that this information will be used against them. This will make it harder for physicians to treat some of our most vulnerable patients and represents a significant breach of trust between physician and patient.

Dangerous criminals should be punished and gunrelated violence should be reduced. These are worthy goals; however, a law that requires physicians to report gunshot wounds will do little to help achieve them. Rather, it will cause physicians to forsake a fundamental promise they make to their patients - to keep their information confidential - and will cause many patients to question whether they can trust their physicians with vital information.
Merril Pauls is with the Departments of Emergency Medicine and Bioethics and Jocelyn Downie is with the Health Law Institute and the Faculties of Law and Medicine, Dalhousie University, Halifax, NS.

Competing interests: None declared.

Contributors: Both authors contributed to the conception and writing of the article, analyzed and interpreted the source material and approved the final version.

\section{References}

1. Ovens H, Morrison H, Drummond A, Borgundvaag B. The case for mandatory reporting of gunshot wounds in the emergency department. Ontario Medical Association Section on Emergency Medicine Position Statement. Ont Med Rev 2003;17-22. Available: www.oma.org/pcomm/omr/nov/03 gunshot .htm (accessed 2004 Mar 10).

2. Legislative Assembly of Ontario. 1st sess, 38th Parliament, sec 6B, Private members' motion 6. Available: www.ontla.on.ca/documents/status_of_business 138_parliament_session_1/section_6b.htm (accessed 2004 Mar 10).

3. Hung K. Firearm statistics (updated tables). Table 14. Ottawa: Research and Statistics Division, Department of Justice; March 2000. Available: www.cfc-ccaf.gc.ca/en /research/publications/stats/pdf/updated-en.pdf (accessed 2004 Mar 10).

4. Hung K Firearm statistics (updated tables). Table 17. Ottawa: Research and Statistics Division, Department of Justice; March 2000. Available: www.cfc-ccaf.gc.ca/en /research/publications/stats/pdf/updated-en.pdf (accessed 2004 Mar 10).

5. Fisher H, Drummond A. A call to arms: the emergency physician, international perspectives on firearm injury prevention and the Canadian gun control debate. 7 Emerg Med 1999;17(3):529-37.

6. Smith v. Fones [1999] 1 SCR 455.

Correspondence to: Merril Pauls, Department of Bioethics,

5849 University Ave., Dalhousie University, Halifax NS

B3H 4H7; fax 902 494-3865; merril.pauls@dal.ca

\section{Why mandatory reporting of gunshot wounds is necessary}

\section{A response from the OMA's Executive of the Section on Emergency Medicine}

\section{Howard Ovens}

ß See related articles pages 1255 and 1258

$\mathrm{I}$ t has been almost 4 years since I received a call from one of my staff physicians looking for guidance because the police were in our emergency department demanding information. A shooting victim was refusing to tell the police anything. The police wanted us to provide the patient's identifying information and argued that it was not privileged. They were frustrated because they felt they did not have enough information to support obtaining a warrant (or that it would take too long). We stood our ground: no warrant, no information. We later contacted colleagues and found that many of them had faced similar situations and that some of them routinely collaborated with police, in most cases because they thought they were legally required to do so.

In the aftermath of the event in our emergency department, we checked with authorities to assure ourselves that our position was legally and professionally sound. We talked to a wide range of individuals, including experts in pubic health, injury prevention and gun control, and found that many thought gunshot wounds were already reportable. The Executive of the Section on Emergency Medicine of the Ontario Medical Association (OMA) took on the challenge of reviewing the problem and suggesting improvements.

Following a literature search, a survey of our members and much debate, we concluded that mandatory reporting of gunshot wounds was justified. We published our results as a position statement that appeared in November, ${ }^{1}$ at a time when gun violence was a hot topic in Toronto. It garnered media attention and many positive responses, but for some we clearly struck a nerve. In this issue of $C M A 7$, Pauls and Downie speak out against our position (see page 1255). ${ }^{2}$ On behalf of the Executive of the OMA's Section on Emergency Medicine, I would like to address their criticisms. 